\title{
MICROALBUMINURIA AS AN INDEPENDENT RISK FACTOR FOR HEART FAILURE IN THE ELDERLY PATIENTS WITH TYPE 2 DIABETES MELLITUS
}

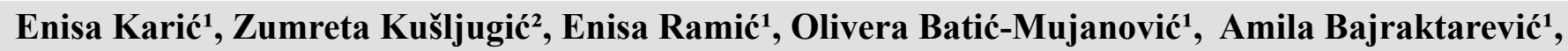 \\ Larisa Hudić Dizdarević², Sabina Kušljugićc ${ }^{3}$, Ena Karićc ${ }^{4}$ Miralem Musićs
}

(C) 2019 by Acta Medica Saliniana ISSN 0350-364X

DOI: $10.5457 / 496$

Enisa Karićı, Zumreta Kušljugić2, Enisa Ramićı, Olivera BatićMujanovićı, Amila Bajraktarevićı, Larisa Hudić Dizdarevićz, Sabina Kušljugićz, Ena Karić4, Miralem Musić5

\section{Afiliations:}

1Primary Health Care Center and Polyclinics „Dr Mustafa Šehović,, Tuzla, 2University Clinical Center Tuzla, Clinics for Internal Medicine, Cardiovascular, 3 University of Tuzla Faculty of Medicine, 4University of Sarajevo Faculty of Stomatology, 5University of Sarajevo Faculty of Medicine, Department of of Patophysiology

\section{Received:}

13.02.2019.

\section{Accepted:}

01.11.2019.

Corresponding author:

Enisa Karić,

Ismet Mujezinović 2, 75 ooo Tuzla, Bosnia and Herzegovina, Phone:

Mob: +387 61959 305,

e-mail: ena.k@bih.net.ba

Funding: none

Competing interests: none

\section{ABSTRACT}

\section{Introduction:}

The study evaluated of microalbuminuria as a predictor of heart failure in patients with diabetes mellitus type 2 .

Materials and methods:

The prospective study conducted in a period of time from o1-Feb-2007 to o1-Feb-2010. The study included 100 patients with type 2 diabetes, who had diabetes longer than 5 years. All subjects (average age $66 \pm 10$ years, $33 \%$ male, $67 \%$ female) were tested for the presence of microalbuminuria, and 50 patients had microalbuminuria. The second group comprised 50 patients without of microalbuminuria with diabetes mellitus type 2.

Results:

In the patients with microalbuminuria and diabetes mellitus were found $22 \%$ of heart failure and $6 \%$ in the second group. Average time to the occurance of heart failure in the first group was 32,5 months, in the second group was 35,3 months.

\section{Conclusions:}

The results show that microalbuminuria is an independent risk factor for heart failure in patients with diabetes mellitus type 2 and microalbuminuria. Patients without microalbuminuria had 3,7 less likely to development heart failure compared to patients with microalbuminuria and diabetes mellitus.

Key words: microalbuminuria, heart failure, diabetes mellitus type 2.

\section{INTRODUCTION}

In the Framingham study, it was estimated that diabetics have two to five times higher incidence of heart failure (HF) than people who do not have diabetes (1). United Kingdom Prospective Study (UKPDS) showed that every increase of $1 \%$ in $\mathrm{HbAic}$ was associated with increased risk for HF by $19 \%$ (2), and by $18 \%$ in the study DIABHYCAR (the non-insulindependent diabetes, hypertension, microalbuminuria or proteinuria, Cardiovascular events, and Ramipril) (3). The Heart Outcome Prevention Evaluation (HOPE) study showed that the presence of microalbuminuria in patients with type 2 diabetes mellitus increases the relative risk for cardiovascular events by 1.83 and by 3.23 for hospitalization for heart failure. For every $0.4 \mathrm{mg} / \mathrm{mmol}$ increase in albumin / creatinine rate, relative risk for major cardiovascular events was increased by $5.9 \%$. (4). This together is disabling, fatal disease (5). The most common causes of HF are hypertension and coronary heart disease.
Other cardiovascular risk factors for HF are left ventricular hypertrophy, valvular heart disease, diabetes mellitus, cigarette smoking and obesity (5).

Risk factors independently increasing cardiovascular risk in diabetic patients are as follows: smoking, hypertension, lipid disorder, disorder of renal function and hyperglycemia. Microalbuminuria was added to the traditional risk factors, as a new sensitive marker for renal and cardiovascular risk and as a marker for impaired endothelial function (6). Microalbuminuria develops from progressive, subclinical, structural changes in the kidneys. Microalbuminuria is a 24-hour urinary albumin excretion (UAE) of 30-300 mg (20-200 $\mu \mathrm{g} / \mathrm{min}$ ) or urinary albumin: creatinine ratio (UACR) of $2.5-30 \mathrm{mg} / \mathrm{mmol}$ in men, $3.5-30 \mathrm{mg} / \mathrm{mmol}$ in women (7). Analysis of 24-hour urine is the gold standard for the detection and quantification of increased albumin excretion. But, since this is painstaking search for the patient, practical alternatives have been proposed as the determination of albumin in the 
urine collected during the night or in a single sample midstream of the first morning urine. Due to the variable excretion of albumin in the urine, a positive finding of microalbuminuria should be confirmed by repeated tests on several occasions (positive results in two of the three samples tested). Albumin excretion increased above the normal range may occur after major physical exertion within 24 hours, urinary tract infections and in case of increased body temperature (fever).

The prevalence of diabetes mellitus in the population with heart disease is $20 \%(8)$. During the last decade the management of heart disease has significantly advanced and improved in clinical outcome through pharmacological inhibition of neurohumoral system (9). Despite this fact, half of these patients died within four years, therefore the need for better prevention or therapeutic strategies was highlighted (10). There is a strong interest in risk-markers for the prediction of heart failure, such as biomarkers of endothelial dysfunction and inflammation (11).

\section{GOAL}

The objective of the study was to examine the relation between increased urinary albumin / creatinine rate (microalbuminuria) and the occurrence of heart failure in patients with Type 2 diabetes mellitus.

\section{MATERIAL AND METHODS}

The study was conducted as a prospective controlled study in regional outpatient family clinic / family medicine center Simin Han of the Health Center Tuzla for the period from o1-Feb-2007 to o1-Feb-2010. 182 patients with Type 2 diabetes mellitus were registered. The study included 100 patients, average age $66 \pm 10$ with a minimum age of 44 and maximum of 86 years (33\% men, $67 \%$ women). The patients had a positive history of type 2 diabetes based on the criteria of the World Health Organization (WHO) from 1999 (13). All subjects had type 2 diabetes mellitus for more than five years. Patients with type 1 diabetes, urinary tract infection, acetonuria, hematuria, and those who had confirmed diagnosis of heart failure were excluded from the study. Subjects were divided into two groups. $\mathbf{1}^{\text {st: }}$ The test-group - subjects who have type 2 diabetes with microalbuminuria (50 patients). $\mathbf{2}^{\text {nd: }}$ The controlgroup - subjects who have type 2 diabetes without microalbuminuria (50 patients).

Microalbuminuria in urine was determined after examination of the sediment in the urine. Proteinuria was determined using test strips for urine. If the test strip show negative proteinuria, microalbuminuria was determined by using albumin / creatinine ratio. Urinary albumin concentration was measured using an enzyme-linked immunosorbent assay (ELISA). Urinary concentration is measured using an enzymatic colorimetric method. As recommended by the National Kidney Foundation (NKF) (14), in screening for quantitative determination of albumin in the urine, albumin / creatinine ratio was calculated for all subjects. In case that the first albumin / creatinine ratio is less than $2.5 \mathrm{mg} / \mathrm{mmol}$ in men and less than $3.5 \mathrm{mg} / \mathrm{mmol}$ in women, the screening was repeated in one year. Men who had result of the albumin / creatinine ratio to be greater than $2.5 \mathrm{mg} / \mathrm{mmol}$, and greater than $3.5 \mathrm{mg} / \mathrm{mmol}$ in women, were studied for the persistence of microalbuminuria for three to six months (7). During the study, the urine was tested for the presence of microalbuminuria every six months. Finding of microalbuminuria (2.5 to $30 \mathrm{mg} / \mathrm{mmol}$ for men, 3.5 to $30 \mathrm{mg} / \mathrm{mmol}$ for women) was considered positive if urine sediment was normal and there was absence of physical exertion for 24 hours before testing. At beginning of the study, clinical-lab parameters were determined in all patients, as follows: history, determined clinical status, electrocardiographic, radiographic and ultrasonic examination of the heart, total cholesterol, triglycerides, HbAic, serum creatinine, creatinine clearance, smoking status, blood pressure, body mass index (BMI), the central waist size. Clinical examination, total serum cholesterol, serum triglycerides, HbAic, serum creatinine, blood pressure, body weight, creatinine clearance and electrocardiographic recording of the heart were repeated every six months.

Diagnosis and classification of heart failure was defined by the propositions of European Society of Cardiology (8). Patients with type 2 diabetes mellitus were treated according to the algorithm for the management of hyperglycemia in adults (15). The study was in accordance with the Helsinki II Declaration and approved by the local ethics committee.

A multivariate Cox model was used to assess the independent prognostic value of baseline characteristics on the risk of HF. The following variables were considered prospectively: age, sex, BMI, systolic and dyastolic blood pressure, smoking $>15$ cigarettes per day, HbAic, serum creatinine, UAC. A backward procedure was used to keep only variables with a P value $<0.05$ Hazard Ratios and $95 \%$ Cis used to describe the predictive value of each variable. A Kaplan-Meier survival curve was used to show the time of occurrence of newly diagnosed HF during the follow-up period.

\section{RESULTS}

Clinical and biochemical characteristics of patients with type 2 diabetes mellitus with and without microalbuminuria (albumin / creatinine ratio from 2.5 to $30 \mathrm{mg} / \mathrm{mmol}$ for men and from 3.5 to $30 \mathrm{mg} / \mathrm{mmol}$ for women) are shown in Table 1.

Data are presented as the arithmetic average with standard deviation $( \pm \mathrm{SD})$

Average values of HbAic in the test group were 8.94 $\pm 2.51 \%$, while in the control group average values were $7.97 \pm 2.02 \%$. There is statistically significant difference between control and test groups in HbAic 
(95\% CI $=0.06$ to 1.87$)$. HbAic values were increased in both groups $(\mathrm{t}=\mathbf{2 . 1 1} \mathrm{df}=98, \mathrm{p}=0.037)$ indicating poor glycemic control. Both groups of patients had an increased body mass index, increased central waist size, hypertension, hypertriglyceridemia. The test group had an average of $0.97 \mathrm{mmol} / \mathrm{l}(95 \% \mathrm{CI}=0.45$ to 1.50) higher triglyceride levels compared to the control group, which was statistically significant $(\mathrm{t}=3.69$, $\mathrm{df}$
Figure 1: Distribution of respondents according to the value of the albumin /creatinine ratio in urine expressed in $\mathrm{mg} / \mathrm{mmol}$

$\mathbf{2 2} \%$ of participants in the group of diabetic patients with microalbuminuria developed heart failure, and only $6 \%$ in the control group. Occurrence of heart

\begin{tabular}{|c|c|c|c|c|c|c|c|c|}
\hline & \multicolumn{4}{|c|}{50 patients with microalbuminuria } & \multicolumn{3}{|c|}{50 patients without microalbuminuria } & \multirow[b]{2}{*}{ P-MW } \\
\hline & Xsr & SD & Xsr & SD & $\mathrm{t}$ & $P$ & $z$ & \\
\hline Age (years) & 65.40 & 8.89 & 65.60 & 9.15 & -0.11 & 0.912 & -0.20 & 0.841 \\
\hline Men, $n(\%)$ & $34 \%$ & & $32 \%$ & & 0.96 & 0.96 & & \\
\hline $\begin{array}{l}\text { Duration of disease } \\
\text { (years) }\end{array}$ & 11.48 & 6.57 & 10.60 & 6.16 & 0.69 & 0.491 & -0.733 & 0.464 \\
\hline Blood pressure & 142.80 & 20.48 & 139.40 & 16.74 & 0.91 & 0.366 & -1.01 & 0.312 \\
\hline \multicolumn{9}{|l|}{ Systolic } \\
\hline Diastolic & 84.70 & 9.92 & 84.40 & 8.43 & 0.16 & 0.871 & -0.426 & 0.670 \\
\hline $\begin{array}{l}\text { Glycosylated hemoglobin } \\
\text { (HbA1c) \% }\end{array}$ & 8.99 & 2.60 & 8.01 & 2.02 & 2.11 & $0.037^{*}$ & -2.286 & $0.022^{*}$ \\
\hline Urinalysis & 7.55 & 5.13 & 1.23 & 0.79 & 13.08 & $<0.0001^{*}$ & -8.570 & $<0.0001^{*}$ \\
\hline \multicolumn{9}{|l|}{$\begin{array}{l}\text { Albumin/creatinine ratio } \\
\text { (mg/mmol) }\end{array}$} \\
\hline $\begin{array}{l}\text { Total cholesterol } \\
(\mathrm{mmol} / \mathrm{l})\end{array}$ & 5.53 & 1.21 & 5.57 & 1.30 & -0.15 & 0.881 & -0.038 & 0.970 \\
\hline $\begin{array}{l}\text { Serum triglycerides } \\
(\mathrm{mmol} / \mathrm{l})\end{array}$ & 2.86 & 1.47 & 1.92 & 1.07 & 3.66 & $<0.0001^{*}$ & -3.482 & $<0.0001^{*}$ \\
\hline Serum creatinine $(\mu \mathrm{mol} / \mathrm{l})$ & 83.33 & 36.89 & 75.66 & 25.66 & 1.21 & 0.230 & -0.810 & 0.418 \\
\hline $\begin{array}{l}\text { BMI (Body mass } \\
\text { index) } \mathrm{kg} / \mathrm{m} 2\end{array}$ & 30.02 & 4.34 & 29.66 & 4.60 & 0.40 & 0.688 & -0.601 & 0.548 \\
\hline $\begin{array}{l}\text { Central waist } \\
\text { size }(\mathrm{cm})\end{array}$ & 106.69 & 15.03 & 104.10 & 16.41 & 0.82 & 0.413 & -1.010 & 0.271 \\
\hline $\begin{array}{l}\text { Creatinine clearance } \\
\left(\mathrm{ml} / \mathrm{min} / 1.73 \mathrm{~m}^{2}\right)\end{array}$ & 84.95 & 28.86 & 85.23 & 30.27 & -0.05 & 0.963 & $\begin{array}{l}-0.021 \\
=\end{array}$ & 0.983 \\
\hline Calculated using & & & & & & & & \\
\hline Cockroft-Gault equation & & & & & & & & \\
\hline
\end{tabular}

$=98, \mathrm{p}<0.001)$. Also, the group had insignificantly higher values of systolic blood pressure compared to the control group. The average duration of diabetes mellitus type 2 in both groups was more than 10 years. failure is significantly increased in patients with microalbuminuria and diabetes mellitus type $2\left(\mathrm{X}^{2}=\right.$ $5 \cdot 32, \mathrm{df}=1, \mathrm{p}=0.02$ ), Figure 2 .

Test group had a significantly higher average value of the albumin / creatinine ratio $(t=13.08, d f=98, p$ $<0.0001$ ), Figure 1. 


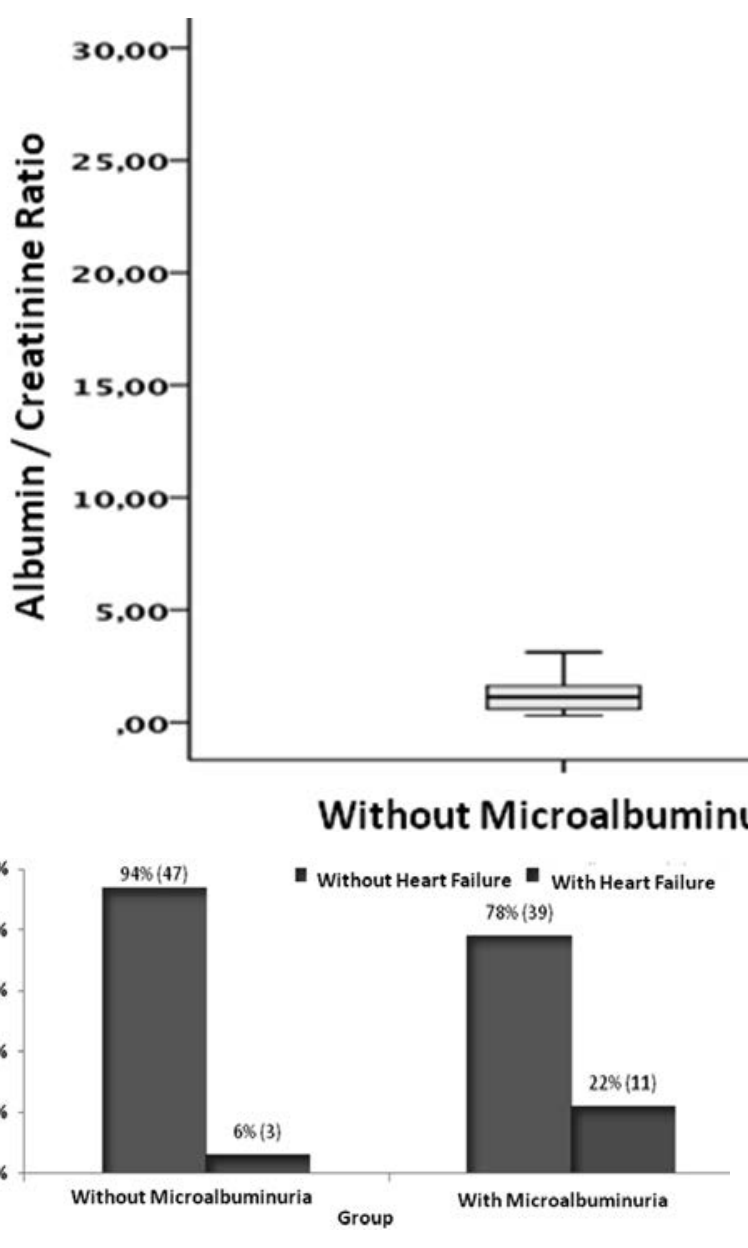

Figure 2: Distribution of heart failure, diabetic patients with and without microalbuminuria

Kaplan-Meier analysis for the occurrence of heart failure in diabetic patients shows that the average time to the occurrence of heart failure in the test group (with microalbuminuria) was 32.5 months $(95 \% \mathrm{CI}=$ 30-35 months), while in the control group (without microalbuminuria) was 35.3 months $(95 \% \mathrm{CI}=33.9$ to 36.6). This difference was statistically significant $\left(\mathrm{X}^{2}=4.65, \mathrm{df}=1, \mathrm{p}=0.03\right)$. Comparative review of the Kaplan-Meier's curve is shown in Figure 3.

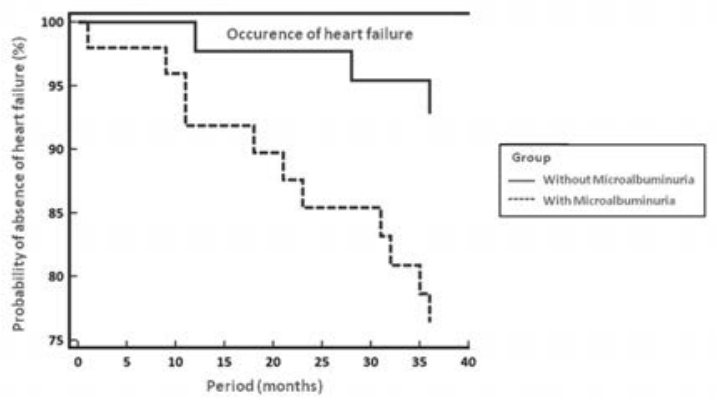

Figure 3: Comparison of the Kaplan-Meier curves for the occurrence of heart failure in diabetic patients with microalbuminuria (red dotted line) and without microalbuminuria (blue solid line)

Cox regression analysis determined that the hazard ratio (HR) for the control group, 0.27 ( $95 \% \mathrm{CI}=0.11$ to

It was found that small increases in urinary albumin / creatinine ratio in patients with diabetes mellitus type 2 is defined as microalbuminuria and is a predictor for heart failure. $22 \%$ of diabetic patients with microalbuminuria develops heart failure, and only $6 \%$ without microalbuminuria. Patients with type 2 diabetes mellitus who developed heart failure were elderly, had significantly higher value of microalbuminuria, higher HbAic and higher levels of triglycerides. Although we found insignificantly increased value of systolic blood pressure in patients with heart failure and microalbuminuria, relation between blood pressure and heart failure could not be found.

Glycemic control was analyzed using HbAic (glycosylated hemoglobin, which determines the level of blood glucose for a period of last three months). Test group patients (with microalbuminuria) had significantly higher result of HbAic, and one of the reasons for poor gluco-metabolic control was target value of HbAic $6.5 \%$, based on the guidelines of the European Association. Another reason for poor metabolic control of glucose in our study were older patients with associated comorbidities. Despite persistent education on lifestyle changes, it proved difficult for patients to change their traditional nutritional habits, since the study was conducted in a rural area.

Our results show that heart failure occurs significantly earlier in patients with type 2 diabetes mellitus with microalbuminuria compared to patients without microalbuminuria and they have 3.7 times more chance to develop heart failure, which is in accordance 
with data from corresponding literature $(3,4)$.

The relationship between diabetes and heart failure is very complex and it has bidirectional nature. Patients with diabetes are at high risk for developing HF, also the patients with HF are at high risk for developing insulin resistance and diabetes, due to activation of the renin-angiotensin-aldosterone system (RAAS). It was proved that the reduction of microalbuminuria with the angiotensin receptor blocker treatment was associated with reduced risk for heart failure (12).

Cardiovascular diseases with their frequency of occurence, epidemic momentum, sociomedical consequences and high mortality rate are becoming the major problem in modern medicine. The highest mortality rate from these diseases is in developed countries, then in countries in transition and the lowest is in poorly developed countries. However, while mortality from cardiovascular diseases in developed countries declines due to preventive measures, in developing countries and countries transition it increases. Our country belongs to the group of countries in transition and it has steady increase in morbidity and mortality from cardiovascular diseases. Heart failure is an expensive, disabling cardiovascular disease. Our study indicates the necessity for stronger preventive measures, the health centers should open counseling for patients with heart failure, including continued education, changing lifestyles, counseling and support, as an integral part of treatment. Priorities for cardiovascular prevention are definitely patients with already established cardiovascular disease and patients who are at high risk for cardiovascular disease, such as patients with type 2 diabetes mellitus and microalbuminuria.

Reduction in albuminuria for 50\% leads to reduction of the heart failure risk for $27 \%$ (12). The presence of atherosclerotic disease, base microalbuminuria and HbAic values are indicators for development of heart failure in future (3). The occurrence of heart failure is a major prognostic turn in the life of patients with Type 2 diabetes mellitus.

\section{CONCLUSION}

Microalbuminuria is a predictor of heart failure in patients with high cardiovascular risk, such as patients with diabetes mellitus type 2 and hypertension. Patients with type 2 diabetes and microalbuminuria significantly earlier and more often develop heart failure compared to those with the normoalbuminuria. Occurrence of heart failure in patients with diabetes mellitus type 2 can be delayed by early screening urine for microalbuminuria using urinary albumin / creatinine ratio, earlier introduction of anti-diabetic therapy, with long-term gluco-metabolic control by monitoring HbAic value. With introduction of early antihypertensive therapy to block the RAAS we prevent the occurence and progression of microalbuminuria as well as with the introduction of early therapy for modifying cardiovascular risk factors.

\section{REFERENCES}

1. Kannel WB, McGee DL .Diabetes and cardiovascular disease: The Framingham study. JAMA. 1979 May 11;241(19):2035-8.doi:10.1001/ jama.1979.03290450033020

2. Intensive blood-glucose control with sulfonylureas or insulin compared with conventional treatment and risk of complications in patients with type 2 diabetes (UKPDS 33). UK Prospective Diabetes Study (UKPDS) Group [No author listed]. Erratum in Lancet 1999 Aug 14; 354 (9178):602. doi.org/So140-6736(98)07019-6

3. Vaur L, Gueret P, Lievre M, Chabaud S, Passa P. Development of congestive heart failure in type 2 diabetic patients with microalbuminuria or proteinuria: observations from the DIABHYCAR (type 2 DIABetes, Hypertension, CARdiovascular Evants and Ramipril) study. Diabetes Care. 2003 Mar; 26(3)855-6o.doi.org/10.2337/ diacare.26.3.855

4. Gerstein MC, Mann JF, Zi Q, et.al.HOPE Study Invesigators. Albuminuria and risk of cardiovascular evants, death, and heart failure in diabetic and nondiabetic individuals. JAMA. 2001 Jul 25; 286(4):421-6.doi:10.1001/jama.286.4.421

5. Ingelsson E, Sundstrom J, Lind L,et. al.Low grade albuminuria and the incidence of heart failure in a community-based cohort of elderly men. Eur Heart J. 2007 Jul;28(14):1739-45.doi.org/10.1093/ euroheartj/ehmizo

6. De Zeeuw D. Microalbuminuria, just a marker for cardiovascular disease, or is it more? J Am Soc Nephrol. 2005 june;16:1883-1885.doi:10.1681/ ASN.2005050524.

7. Karalliedde J, Viberti G . Microalbuminuria and cardiovascular risk. Am J Hypertens.2004 Oct; $\quad$ 17(10):986-93.doi.org/10.1016/j. amjhyper.2004.08.010

8. Dickstein K, Cohen-Solal A, Filippatos G, et.al. ESC guidelines for the diagnosis and treatment of acute and chronic heart failure 2008; the Task Force for the diagnosis and treatment of acute and chronic heart failure 2008 of the European Society of Cardiology. Eur Heart J. 2008 Oct; 29(19):2388-442.doi.org/10.1093/euroheartj/ ehn3o9

9. Rich MW, Beckham V, Wittenberg C, et.al.A multidisciplinary intervention to prevent the readmission of elderly patients with congestive heart failure. N Engl J Med. 1995 Nov;333:1190-5. doi:10.1056/NEJM199511023331801

10.Cowie MR, Wood DA, Coats AJ, et.al.Survival of patients with a new diagnosis of heart failure: a population based study.Heart.200o May; 83 (5):505-510.doi:10.1136/heart.83.5.505

11. Braunwald E. Biomarkers of Heart Failure. N Engl Med.20o8 May;358:2148-59.doi:10.1056/ NEJMrao8oo239 
12. De Zeeuw D, Remuzzi G, Parving HH, et.al. Albuminuria a terapeutic target for cardiovascular protection in type 2 diabetic patients with nephropathy.Circulation. 2004 Aug;110:921-927. doi.org/10.1161/o1.CIR.oooo139860.33947.28

13. Definition, diagnosisand classification of diabetes mellitus and its complication. Report of WHO consultation. Part 1:Diagnosis and classification of diabetes mellitus. Authors:World Health Organisation.Department of Noncomunicable Disease Surveillance. Issue date:1999.Publisher: Geneva.

14.Levey AS, Coresh J, Balke E, Kausz AT, Levin A, Steffes MW, Hogg RJ, Perrone RD, Lau J, Eknoyan G. National Kidney Foundation practice guidalines for chronic kidney disease: evaluatin, classification and stratification. Ann Intern Med. 2003 Jul; 139(2):137-47.doi:10.7326/ooo3-4819139-2-200307150-00013

15. Ryden L, Standl E, Bartnik M, Van den Berghe G, Betteridge J, de Boer MJ et al. Guidelines on diabetes, pre-diabetes and cardiovascular diseases: executuve summary. The Task Force on Diabetes and Cardiovascular Diseases of the European Society of Cardiology (ESC) and of the European Association for the Study of Diabetes (EASD). Eur Heart J: 2007 Jan;28(1):88-136.doi. org/10.1093/euroheartj/ehl26o

16.Dinneen SF, Gerstein HC. The association of microalbuminuria and mortality in noninsulin dependent diabetes mellitus. Arch Intern Med. 1997 Jul;157:1413-8.doi:10.1001/ archinte.1997.00440340025002 